\title{
ANALYSIS OF A COMMERCIAL PORTABLE LITHIUM-ION BATTERY UNDER LOW CURRENT CHARGE- DISCHARGE CYCLES
}

\author{
Stephany Pires da Silva, Paulo Rogério Catarini da Silva, Alexandre Urbano e Jair Scarminio*
}

Departamento de Física, Universidade Estadual de Londrina, 86057-970, Londrina - PR, Brasil

Recebido em 16/11/2015; aceito em 18/04/2016; publicado na web em 17/06/2016

\begin{abstract}
The dependence between the transferred charge and the corresponding transference time to charge and discharge a portable cell phone Li-ion battery $\left(\mathrm{LiCoO}_{2} / \mathrm{C}\right)$ under cycles of low intensity currents was studied in detail. The voltage curve profile between 3.0 and 4.2 $\mathrm{V}$ and the charging and discharging time are strongly influenced by the applied current intensity. A linear dependence between the stored and extracted charges, into and from the battery, with the intensity of applied current was also observed. Allometric equations were found to describe the correlation between the charge transference time and the applied current intensity to charge and discharge the battery.
\end{abstract}

Keywords: lithium-ion battery; charging and discharging; CC protocol, low currents.

\section{INTRODUCTION}

Batteries of Li-ions (BILs) operate over reversible electrochemical oxidation and reduction reactions between a $\mathrm{Li}_{\mathrm{x}} \mathrm{MO}_{2}$ cathode (M: Co, Ni, Mn and its compounds) and a carbon (graphite) based anode, with Li salts dissolved in organic compound solution as the electrolyte. Under conditions of electrolyte chemical stability and redox reaction reversibility, the batteries of $\mathrm{Li}_{\mathrm{x}} \mathrm{CoO}_{2}$ cathodes operate between the voltages of 3.7 to $4.2 \mathrm{~V}$, with the $\mathrm{Li}$ concentration in the $0.5<\mathrm{x}<1.0$ range. $^{1}$ The spontaneous reaction (in discharge) occurs by the electrochemical insertion of $\mathrm{Li}^{+}$cations into the $\mathrm{Li}_{\mathrm{x}} \mathrm{CoO}_{2}$ compound (under Co reduction) in conjunction with the oxidation of the $\mathrm{C}$ anode (with the output of $\mathrm{Li}^{+}$ions from the $\mathrm{C}$ material to the electrolyte), lowering the battery voltage. When $\mathrm{x} \cong 1.0$ the battery is fully discharged and external electric power should be provided to cathode oxidation and anode reduction reactions. When $\mathrm{x}=0.5$ the battery is fully charged and its voltage is $4.2 \mathrm{~V}^{2}$ Due to the redox reaction simplicity, the BIL's are very stable devices when properly operated between its voltage and current limits. However, its charge capacity decreases progressively with the number of charge-discharge cycles.

Different protocols have been proposed to charge the BILs, including: application of a constant current followed by a constant voltage $(\mathrm{CC}+\mathrm{CV}$ protocol $),{ }^{3}$ current pulses,${ }^{4}$ continuously decreasing or multi-stage currents, ${ }^{5,6}$ constant current (CC), ${ }^{7}$ and other strategies and algorithms that seek to maximize the storage charge and minimize the charging time. ${ }^{8}$ They have in common the feature that at some stage in the charging process, a continuous, variable or pulsed current is applied, which may be preceded or followed by the application of a voltage.

Commercial battery chargers commonly use the $\mathrm{CC}+\mathrm{CV}$ protocol, where a constant current (CC) is applied until the battery reaches 4.2 $\mathrm{V}$, followed by a step where the voltage is maintained at this value (CV) until the current between the battery electrodes fall to a predetermined low value. ${ }^{3}$ Studies show that the $\mathrm{CC}$ step in the $\mathrm{CC}+\mathrm{CV}$ charging protocol can charge up to $80 \%$ or even more of the battery charge capacity, for currents up to $0.5 \mathrm{C} .{ }^{7}$ The storage charge and the charging time will depend, in this step, on the battery states of charge (SOC) and health $(\mathrm{SOH})$ and on the intensity of the applied electrical

*e-mail: scarmini@uel.br current, since low charging current intensities imply long charging times and high charge storage, while under highly charging currents (higher than $0.5 \mathrm{C}$ ), the charge stored in the battery will be lower, but within shorter charging times. ${ }^{9}$

Apart from directly influencing the charge capacity and the battery charging time, the intensity of the charging current contributes to the kinetics of formation of the solid-electrolyte interface passivation layer (SEI) on the anode surface, during the first battery charging cycles. ${ }^{10}$ This can be responsible for Li electroplating the graphite anode during the charging processes ${ }^{11,12}$ and for increasing the battery potential during their charging and discharging, due to polarization effects. The SEI, the electrodeposited $\mathrm{Li}$ and polarization potential have influences on battery performance and determine, together with other parameters, its life cycle.

A BIL is discharged when operating as a power sources for electri$\mathrm{cal}$ and electronic devices. The intensity of the discharging current will depend on the power required by the device. The discharging time is a function of the battery SOH, the stored charge in it, the battery SOC, and the current intensity required along the discharge. Discharges can occur under continuous current or even for high-frequency current pulses as in cell phones, in the GSM protocol. ${ }^{13}$

Although many studies about charge and discharge processes on BIL can be found, most of them are performed by applying charging and discharging currents from medium to high intensities (higher than $0.5 \mathrm{C}$ ). We present a detailed analysis of charge and discharge parameters of a commercial cell-phone lithium-ion battery, when submitted to continuous charge and discharge cycles under constant charging and discharging currents of low intensities $(0.04 \mathrm{C}$ to $0.52 \mathrm{C}$ ). The effects of the applied current intensity on the voltage profile, on the charging and discharging time, on the stored charge (charge capacity) and extracted charge (discharge capacity), and the functional dependence between the charging and discharging time with the applied current intensity were studied.

\section{EXPERIMENTAL}

The studies were performed on a commercial $\mathrm{LiCoO}_{2} / \mathrm{C}$ cell phone battery, with nominal discharge capacity equal to $960 \mathrm{~mA} \mathrm{~h}$ (technically the battery charge capacity) and a SOH equal to $98 \%$. These batteries have a prismatic case, both the cathode and anode are strips, with a polymeric insulating separator between them, containing 
the electrolyte. The three strips are wound as a jelly roll and inserted into the battery case.

Table 1 and 2 show the matrices designed for the battery charging and discharging tests, performed under the $\mathrm{CC}$ protocol, as well as the results obtained. The variables studied were: the intensity of the charging $\left(i_{c}\right)$ and discharging $\left(i_{d}\right)$ currents, the corresponding charging $\left(t_{c}\right)$ and discharging $\left(t_{d}\right)$ times, the inserted $\left(Q_{c}\right)$ and extracted $\left(Q_{d}\right)$ charges into and from the battery, respectively (charge and discharge capacities).

In the charging tests (Table 1) $\mathrm{i}_{\mathrm{c}}$ currents equal to $40,80,120$, 200, 300, 400 and $500 \mathrm{~mA}$ (C rate between $0,04 \mathrm{C}$ and 0,52C) were applied to charge the battery from 3.0 to $4.2 \mathrm{~V}$. At $4.2 \mathrm{~V}$, the battery circuit was open $(\mathrm{OCV})$ until equilibrium voltage was reached after 15 minutes, followed by discharges at constant currents, $i_{\mathrm{d}}$, of $-80 \mathrm{~mA}$ (0.8C), $-210 \mathrm{~mA}(0.22 \mathrm{C})$ and $-300 \mathrm{~mA}(0.31 \mathrm{C})$, down to $3.0 \mathrm{~V}$. The OCV assures the relaxation of battery overvoltage before each discharge.

For each one of the seven charging currents, the battery was discharged under the three discharging currents, resulting in twenty one charge-discharge cycles, as shown in Table 1. Discharged to 3.0 $\mathrm{V}$, the battery was kept at this voltage until the current dropped to 5 $\mathrm{mA}$. So, each new charging cycle was started with the battery on the same residual charge and at $3.0 \mathrm{~V}$.

Table 2 shows the test matrix designed to perform the battery discharge studies in $\mathrm{CC}$ of different intensities and the obtained results. The variables were the intensity of the $\mathrm{CC}$ applied to discharge $\left(i_{d}\right)$ the battery, the corresponding discharging time $\left(t_{d}\right)$, the extracted charge $\left(\mathrm{Q}_{\mathrm{d}}\right)$ (discharge capacity) and the $\mathrm{CC}$ and $\mathrm{CC}+\mathrm{CV}$ charging protocols, employed to charge the battery. Discharges were performed after charging at 120 and $500 \mathrm{~mA}$ (CC protocol) and under $500 \mathrm{~mA}+4.2 \mathrm{~V}(\mathrm{CC}+\mathrm{CV}$ protocol $)$. In the $\mathrm{CV}$ step of the $\mathrm{CC}+\mathrm{CV}$ protocol the battery was kept at $4.2 \mathrm{~V}$ until the current decays to 1.0 $\mathrm{mA}$. The $\mathrm{CC}$ discharges were performed at currents equal to $-40,-80$, $-120,-200,-300,-400$ and $-500 \mathrm{~mA}$, as shown in Table 2 . The battery was cycled between 3.0 and $4.2 \mathrm{~V}$. At $4.2 \mathrm{~V}$, the battery circuit was opened for 15 minutes and at $3.0 \mathrm{~V}$ the voltage was maintained until the battery current dropped to $5.0 \mathrm{~mA}$, when a new charging cycle is then started. In total, twenty one charge-discharge cycles were continuously performed, wherein seven discharges were carried out for each one of three charging processes.

A capacity fading experiment was conducted to follow how the charge-discharge cycles performed during all the experiments of this work could change the battery $\mathrm{SOH}$ and, accordingly, have influence on the results to be shown, by continuously cycling an identical battery between 3.0 and 4.2 voltage limits, under the $\mathrm{CC}+\mathrm{CV}$ $(0.7 \mathrm{C}+4.2 \mathrm{~V})$ and $\mathrm{CC}(0.5 \mathrm{C})$ protocols, to charge and discharge the battery, respectively.

An Arbin BT2000 battery tester was used in the charge-discharge experiments, by connecting the auxiliary and work cables to the negative and positive battery poles, respectively.

\section{RESULTS AND DISCUSSIONS}

Figure 1 shows the first three and last three of twenty-one continuous charge-discharge cycles, for the experiments described in Table 1. Similar curves were obtained for the experiments described in Table 2. Results extracted from these curves were displayed on Tables 1 and 2 and on Figures 2 to 5 .

Figure 1 and Figure 2a show that the voltage curve profile between 3.0 and $4.2 \mathrm{~V}$ and the corresponding charging and discharging times are both dependent on the intensity of the applied current. Two distinct regions can be identified in these voltage curves, one for which the voltage rapidly changes in the 3.0 to $3.7 \mathrm{~V}$ range, followed by a second region in which the voltage change more smoothly between 3.7 and $4.2 \mathrm{~V}$, with a profile very dependent on the applied current intensity.

The change in the battery voltage between 3.7 and $4.2 \mathrm{~V}$ is due mainly to $\mathrm{Li}^{+}$insertion (the voltage decreases) and extraction (the voltage increases) into and from the $\mathrm{LiCoO}_{2}$ cathode, as evidenced by the cyclic voltammetries of the $\mathrm{LiCoO}_{2} / \mathrm{Li}$ cell presented in the literature, wherein redox currents are set up only in this voltage

Table 1. Matrix of tests designed to charge the battery with seven CC, each one followed by three CC discharges, and the obtained results for $t_{c}, Q_{c}, t_{d}$ and $Q_{d}$

\begin{tabular}{|c|c|c|c|c|c|c|}
\hline \multirow[b]{2}{*}{ Cycles } & \multicolumn{3}{|c|}{ Charging } & \multicolumn{3}{|c|}{ Discharging } \\
\hline & $\begin{array}{c}\mathrm{i}_{\mathrm{c}} \\
(\mathrm{mA})\end{array}$ & $\begin{array}{l}\mathrm{t}_{\mathrm{c}} \\
(\mathrm{h})\end{array}$ & $\begin{array}{c}\mathrm{Q}_{\mathrm{c}} \\
(\mathrm{mA} \mathrm{h})\end{array}$ & $\begin{array}{c}\mathrm{i}_{\mathrm{d}} \\
(\mathrm{mA})\end{array}$ & $\begin{array}{l}\mathrm{t}_{\mathrm{d}} \\
(\mathrm{h})\end{array}$ & $\begin{array}{c}\mathrm{Q}_{\mathrm{d}} \\
(\mathrm{mA} \mathrm{h})\end{array}$ \\
\hline $1^{\mathrm{o}}$ & 40 & 24.13 & 965.4 & -80 & 11.97 & 957.5 \\
\hline $2^{\circ}$ & 40 & 23.91 & 956.2 & -210 & 4.53 & 952.0 \\
\hline $3^{\circ}$ & 40 & 23.90 & 956.2 & -300 & 3.17 & 949.6 \\
\hline $1^{\circ}$ & 80 & 11.76 & 940.6 & -80 & 11.76 & 940.6 \\
\hline $2^{\circ}$ & 80 & 11.76 & 940.7 & -210 & 4.46 & 937.0 \\
\hline $3^{\circ}$ & 80 & 11.75 & 940.2 & -300 & 3.11 & 933.6 \\
\hline $1^{\mathrm{o}}$ & 120 & 7.72 & 925.7 & -80 & 11.56 & 925.2 \\
\hline $2^{o}$ & 120 & 7.71 & 924.7 & -210 & 4.38 & 920.6 \\
\hline $3^{\circ}$ & 120 & 7.70 & 924.4 & -300 & 3.06 & 918.0 \\
\hline $1^{\mathrm{o}}$ & 200 & 4.47 & 894.2 & -80 & 11.16 & 893.0 \\
\hline $2^{\circ}$ & 200 & 4.47 & 893.8 & -210 & 4.24 & 889.7 \\
\hline $3^{\circ}$ & 200 & 4.47 & 894.3 & -300 & 2.96 & 888.2 \\
\hline $1^{\mathrm{o}}$ & 300 & 2.84 & 854.1 & -80 & 10.66 & 853.1 \\
\hline $2^{o}$ & 300 & 2.85 & 854.6 & -210 & 4.05 & 850.5 \\
\hline $3^{\circ}$ & 300 & 2.85 & 853.8 & -300 & 2.82 & 847.4 \\
\hline $1^{\mathrm{o}}$ & 400 & 2.04 & 814.9 & -80 & 10.17 & 813.8 \\
\hline $2^{\circ}$ & 400 & 2.04 & 817.7 & -210 & 3.87 & 813.7 \\
\hline $3^{\circ}$ & 400 & 2.04 & 816.0 & -300 & 2.70 & 809.8 \\
\hline $1^{o}$ & 500 & 1.55 & 775.8 & -80 & 9.68 & 774.5 \\
\hline $2^{\circ}$ & 500 & 1.56 & 783.1 & -210 & 3.71 & 779.2 \\
\hline $3^{\circ}$ & 500 & 1.56 & 784.5 & -300 & 2.60 & 782.0 \\
\hline
\end{tabular}


Table 2. Matrix of tests designed to discharge the battery with seven discharging currents $i_{\mathrm{d}}$, after three different charging processes, and the results obtained for $t_{d}$ and $Q_{d}$

\begin{tabular}{|c|c|c|c|c|c|c|}
\hline \multirow{2}{*}{$\begin{array}{c}\text { Discharging } \\
\text { current } \\
\mathrm{i}_{\mathrm{d}} \\
(\mathrm{mA})\end{array}$} & \multicolumn{2}{|c|}{$\begin{array}{c}\text { Charged at } 120 \mathrm{~mA} \\
\mathrm{Q}_{\mathrm{c}}=(907.9 \pm 2.4) \mathrm{mA} \mathrm{h} \\
\mathrm{t}_{\mathrm{c}}=7.55 \mathrm{~h}\end{array}$} & \multicolumn{2}{|c|}{$\begin{array}{c}\text { Charged at } 500 \mathrm{~mA} \\
\mathrm{Q}_{\mathrm{c}}=(787.0 \pm 4.0) \mathrm{mA} \mathrm{h} \\
\mathrm{t}_{\mathrm{c}}=1.57 \mathrm{~h}\end{array}$} & \multicolumn{2}{|c|}{$\begin{array}{c}\text { Charged CC+CV } \\
\mathrm{Q}_{\mathrm{c}}=(971.4 \pm 0.6) \mathrm{mA} \mathrm{h} \\
\mathrm{t}_{\mathrm{c}}=3.75 \mathrm{~h}\end{array}$} \\
\hline & $\begin{array}{l}\mathrm{t}_{\mathrm{d}} \\
(\mathrm{h})\end{array}$ & $\begin{array}{c}\mathrm{Q}_{\mathrm{d}} \\
(\mathrm{mA} \mathrm{h})\end{array}$ & $\begin{array}{l}\mathrm{t}_{\mathrm{d}} \\
(\mathrm{h})\end{array}$ & $\begin{array}{c}\mathrm{Q}_{\mathrm{d}} \\
(\mathrm{mA} \mathrm{h})\end{array}$ & $\begin{array}{l}\mathrm{t}_{\mathrm{d}} \\
(\mathrm{h})\end{array}$ & $\begin{array}{c}\mathrm{Q}_{\mathrm{d}} \\
(\mathrm{mA} \mathrm{h})\end{array}$ \\
\hline 40 & 22.85 & 910.2 & 20.01 & 791.2 & 24.61 & 972.0 \\
\hline 80 & 11.37 & 907.5 & 9.96 & 790.7 & 12.21 & 969.5 \\
\hline 120 & 7.56 & 905.4 & 6.60 & 788.8 & 8.09 & 967.3 \\
\hline 200 & 4.52 & 903.7 & 3.92 & 782.0 & 4.84 & 966. 0 \\
\hline 300 & 3.00 & 901.0 & 2.61 & 781.8 & 3.21 & 963.3 \\
\hline 400 & 2.25 & 898.1 & 1.95 & 778.9 & 2.41 & 961.0 \\
\hline 500 & 1.79 & 893.0 & 1.55 & 773.0 & 1.92 & 957.1 \\
\hline
\end{tabular}

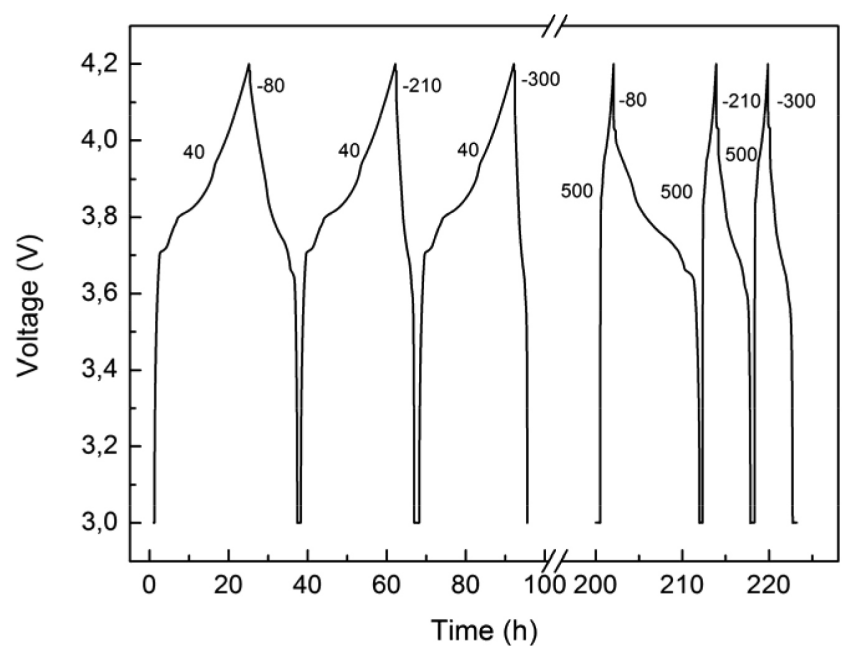

Figure 1. The first three and last three of twenty-one charge and discharge cycles applied to the battery, as described in Table 1. The numbers on the curves are the applied currents (in $\mathrm{mA}$ ) to charge (+) and discharge (-) the battery

range, with an oxidation peak around 3.7 V. ${ }^{14}$ High currents imply fast changes in the concentration of $\mathrm{Li}^{+}$ions into the lamellar planes in the $\mathrm{LiCoO}_{2}$ structure ${ }^{2}$ and, as a consequence, fast changes in the battery voltage in a short time. Under low currents the opposite occurs. Given that the carbon anode voltage does not change more than
$0.2 \mathrm{~V}$ whereas the battery voltage change between 3.7 to $4.2 \mathrm{~V},{ }^{1}$ the concentration of $\mathrm{Li}^{+}$ions into the $\mathrm{LiCoO}_{2}$ cathode accounts for the battery voltage in this range.

The fast voltage increase from 3.0 to $3.7 \mathrm{~V}$ at the beginning of battery charging is due to rapid polarization overvoltage. ${ }^{15} \mathrm{In}$ fact, Figure $2 \mathrm{~b}$ shows the OCV curves after the discharge at $3.0 \mathrm{~V}$ and the charging curves from $3.0 \mathrm{~V}$, for the three currents $(80,300$ and $500 \mathrm{~mA}$ ). Equal overvoltages are observed for the same discharging and charging currents.

Under discharge, the fast change in the battery voltage from 3.7 to $3.0 \mathrm{~V}$ occurs as a consequence of almost full occupancy of the $\mathrm{Li}$ ion sites in the $\mathrm{LiCoO}_{2}$ crystalline structure. So, any further discharge to $3.0 \mathrm{~V}$ will occur by the electrode polarizations, at the expense of fast decreases in the battery voltage.

The charge $Q_{c}$, stored in the battery in the charging from 3.0 to $4.2 \mathrm{~V}$ by the seven currents $i_{c}$, as described in Figure 1 and Table 1, is shown in Figure 3. A linear decrease of the charge capacity with the intensity of the charging current was obtained, a behavior that is also observed from published data for charging currents lower than $1 \mathrm{C}$, but that departs from linearity for higher currents. ${ }^{16,17}$

Figure 3 shows also the extracted charge $\mathrm{Q}_{\mathrm{d}}$ by the seven discharging currents $i_{d}$, after the battery was charged by the 120 and $500 \mathrm{~mA}$ currents and by the $500 \mathrm{~mA}+4.2 \mathrm{~V} \mathrm{CC}+\mathrm{CV}$ protocol, as described in Table 2. The extracted charge also decreases linearly with the intensity of the discharging current, for each of these three battery charging procedures. However, literature data indicates a non-linear

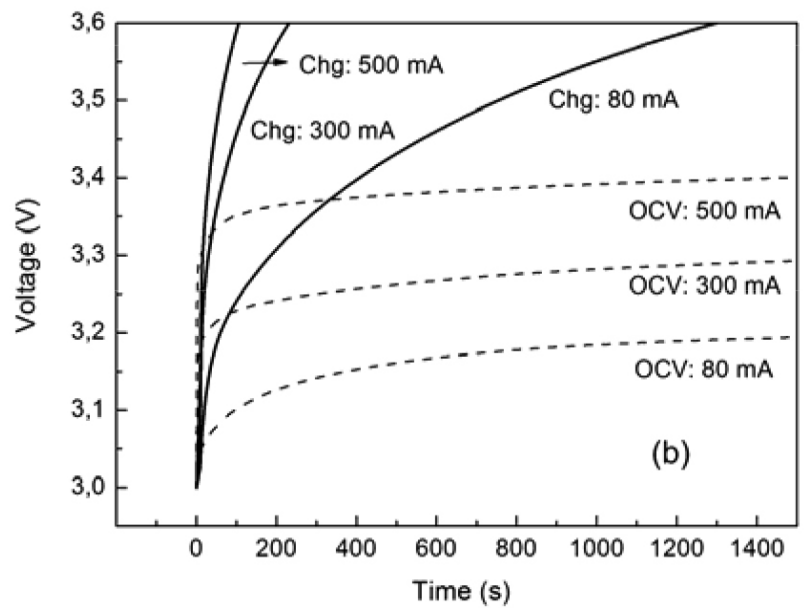

Figure 2. Voltage curves in charging (---) and discharging the battery (-) under various currents (indicated on the curves, in $m A)($ a), the OCV after discharge down to $3.0 \mathrm{~V}(---)$ and charging voltage curves from $3.0 \mathrm{~V}(-)(b)$ 
discharge capacity decreasing for discharge currents higher than $1 \mathrm{C}^{5}$ The observed decrease in the charge and discharge capacities with the current intensity is caused by the polarization overvoltage, with the value being proportional to the current intensity.

Figure 3 (open circles) shows that when charged at $40 \mathrm{~mA}$, the battery charging capacity is $180 \mathrm{~mA} \mathrm{~h}$ greater than when charged at $500 \mathrm{~mA}$. However, after being charged by the 120 and $500 \mathrm{~mA}$ $\mathrm{CC}$ charging currents and by the $\mathrm{CC}+\mathrm{CV}$ protocol, almost all stored charge is extracted from the battery, even at the higher discharging currents: the discharging capacity for the $40 \mathrm{~mA}$ discharging current is only $16.0 \pm 1 \mathrm{~mA}$ h higher than the discharging capacity under the $500 \mathrm{~mA}$ discharging current. This effect stems from the asymmetric kinetics of insertion and extraction of $\mathrm{Li}^{+}$ions into and from the $\mathrm{LiCoO}_{2}$ cathode. The thermodynamic response for this effect is the asymmetry in the charging and discharging voltage curves under de same current intensity, as can be observed in Figure 2a.

The effect of the charging protocol on the battery charging capacity can be observed from Table 2 and Figure 3: battery charge capacities equal to $907.9 \pm 2.3,787.7 \pm 4.0$ and $971.4 \pm 0.6 \mathrm{~mA} \mathrm{~h}$, were obtained for charging at $120 \mathrm{~mA}, 500 \mathrm{~mA}$ and at $500 \mathrm{~mA}+4.2 \mathrm{~V}(\mathrm{CV})$, respectively. The $\mathrm{CV}$ step increases the battery charge capacity in $7 \%$ and $23 \%$ on the charge stored by the 120 and $500 \mathrm{~mA} \mathrm{CC}$ steps, respectively. These results show that the battery SOC depends on the intensity of the charging current applied in the $\mathrm{CC}$ step but also on the charging protocol. A detailed study about the effect of the $\mathrm{CC}$ and $\mathrm{CV}$ protocols on the charge capacity was presented for the $\mathrm{MCMB} / \mathrm{LiCoO}_{2}$ cell. $^{3}$

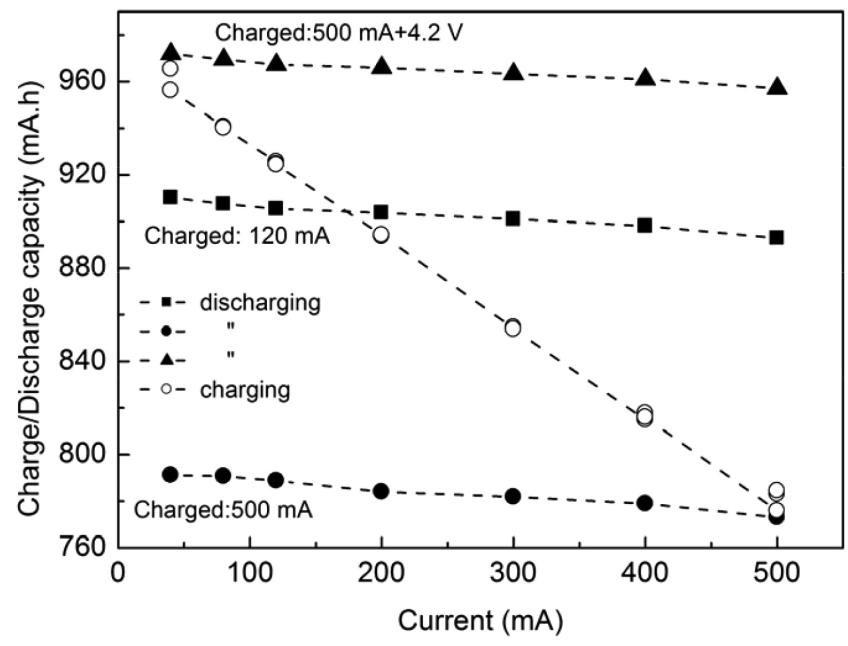

Figure 3. Charge capacity and discharge capacity as function of the current intensity. The battery was discharged after being charged at $120 \mathrm{~mA}, 500 \mathrm{~mA}$ and on $500 \mathrm{~mA}+4.2 \mathrm{~V}$

Figure 4 shows the charge extracted $\left(\mathrm{Q}_{\mathrm{d}}\right)$ in discharges performed at $-80,-210$ and $-300 \mathrm{~mA}$ as a function of the stored charge $\left(Q_{c}\right)$ in the battery for the seven charging currents, as described in Table 1. A linear dependence between $\mathrm{Q}_{\mathrm{d}}$ and $\mathrm{Q}_{\mathrm{c}}$ is observed, with the charge capacity increasing with decreasing charging current intensity. The battery discharge capacity diminishes when the discharging current increases from $-80 \mathrm{~mA}$ to $-300 \mathrm{~mA}$ and this effect is more pronounced the greater the battery charge capacity. The slope of the linear fittings show coulombic efficiencies equals to $0.987,0.973$ and 0.969 for discharges at $-80,-210$ and $-300 \mathrm{~mA}$, respectively.

The time to charge the battery from 3.0 to $4.2 \mathrm{~V}$ and to discharge it from 4.2 to $3.0 \mathrm{~V}$ is very dependent on the current intensity as shown in Figure 5, drawn from data of Table 1 for battery charging

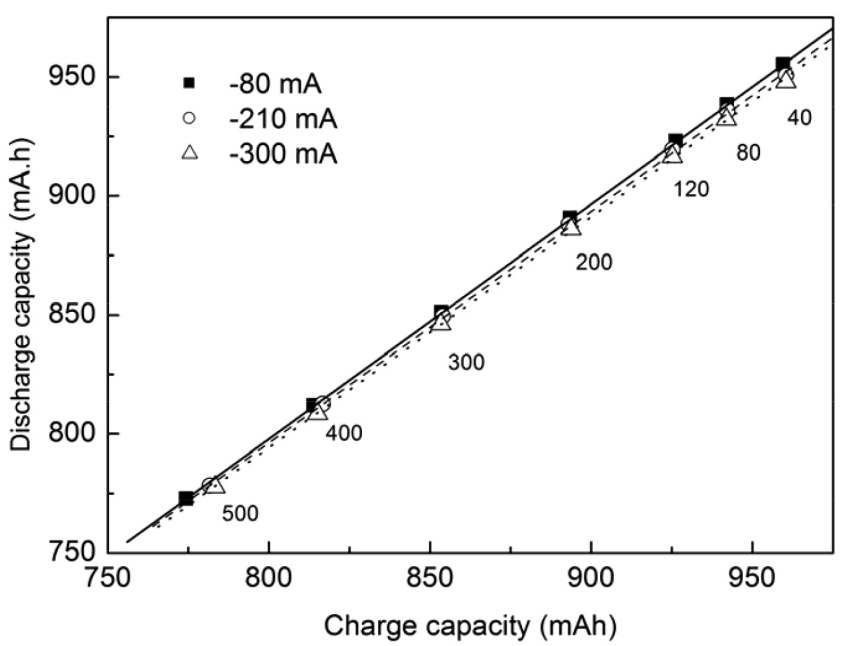

Figure 4. Charge capacity as function of the seven charging currents and the discharge capacity as function of three discharging currents (-80, -210 and $-300 \mathrm{~mA})$. The numbers beside the symbols indicate the charging currents and the lines are linear fittings for the discharge current data

and from data of Table 2, for the three battery dischargings. Both, the charging and discharging times, decreases asymptotically with the current intensity, as also observed in other studies performed on $\mathrm{LiCoO}_{2}$ cells. ${ }^{3,17}$

Figure 5 shows that the discharge time, $t_{d}$, depends on the discharge current intensity, $i_{d}$, but also on the battery state of charge (SOC) before the discharges. At low discharging currents an appreciable difference between the $t_{d}$ values with the battery SOC is observed, that progressively decreases as the discharge current intensity increases. The battery state of health $(\mathrm{SOH})$ must be also considered if it is not new in use. ${ }^{18}$

The experimental data of Figure 5 can be fitted by allometric equations, as shown in Table 3, where the equation on line a) refers to battery charging and the items b), c) and d) refer to battery discharging, for the three chargings described in Table 2.

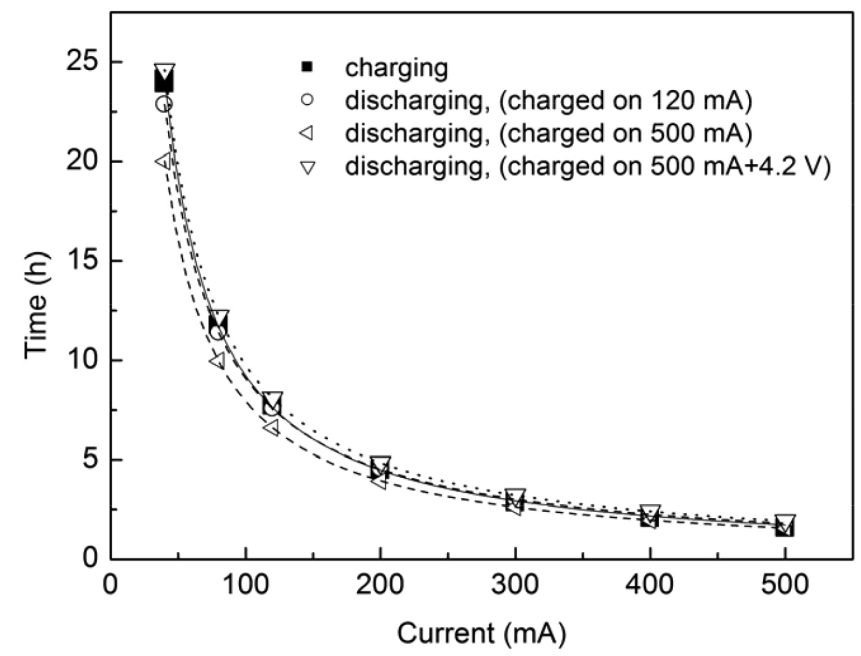

Figure 5. Discharging time (open symbols) and charging time (black symbol) as a function of discharging and charging currents and fitted curves described in Table 3

The fitted equations are similar to those proposed by Peukert ( $t . i^{k}=C$, where $k$ and $C$ are constants) to describe the dependence between the current intensity to discharge a fully charged lead-acid battery and the discharging time. ${ }^{19}$ This equation has been improved 
Table 3. Fitted equations for the charging and discharging times, as a function of applied current. $\mathrm{C}_{5}$ : battery charge capacity measured in a discharge of five hours.

\begin{tabular}{lll}
\hline Data from: & Fitted equation & Charge capacity $\mathrm{C}_{5}(\mathrm{~mA} \mathrm{~h})$ \\
\hline a) charging time $\mathrm{x}$ current, Table 1 data & $\mathrm{t} . \mathrm{i}^{1.043}=1123.0$ & -- \\
b) discharging time $\mathrm{x}$ current, Table 2 data for battery charged on $500 \mathrm{~mA}$ & $\mathrm{t} . \mathrm{i}^{1.010}=828.2$ & 787 \\
c) discharging time $\mathrm{x}$ current, Table 2 data for battery charged on $120 \mathrm{~mA}$ & $\mathrm{t} . \mathrm{i}^{1.007}=938.3$ & 904 \\
d) discharging: time $\mathrm{x}$ current, Table 2 data for battery charged on $500 \mathrm{~mA}+4.2 \mathrm{~V}$ & $\mathrm{t} \cdot \mathrm{i}^{1.011}=1025.2$ & 967 \\
\hline
\end{tabular}

for lithium-ion batteries considering thermal effects, high discharge currents and long discharge times. ${ }^{20}$

Table 3 shows that allometric equations can be employed to fit the data of not only battery discharging but also the data of the battery charging. $k$ values around 1.01 were obtained for the b), c) and d) discharges. The $C$ values can be related to the battery discharge capacity since they increase in the sequence b) to c) to d).

From the allometric equations of Table 3, the discharging current $\left(\mathrm{i}_{5}\right)$ applied to discharge the battery in five hours $\left(\mathrm{t}_{5}=5 \mathrm{~h}\right)$ can be calculated, and from this the corresponding charge $\mathrm{C}_{5}=\mathrm{i}_{5} . \mathrm{t}_{5}$ is obtained, as showed in Table 3 . The $\mathrm{C}_{5}$ value is the charge extracted from the battery in a discharge of 5 hours, after it was fully charged, as described in items b), c) and d) of Table 3. Technically, $\mathrm{C}_{5}$ is the battery charge.

In battery cycling experiments, besides the battery SOC also the battery $\mathrm{SOH}$, or equivalently the charge capacity, should be considered since it decreases with the number of charge-discharge cycles, as showed in Figure 6 obtained from a battery of the same manufacturer and model as employed in this study. It can be seen that for a fresh battery, significant losses in the battery SOH for charge-discharge cycles below than one hundred are not observed. Considering that in the study presented here, no more than sixty charge-discharge cycles were performed on a fresh battery $(\mathrm{SOH}=98 \%)$, the decrease in the battery SOH during all cycles was very small, having a secondary effect on the results presented.

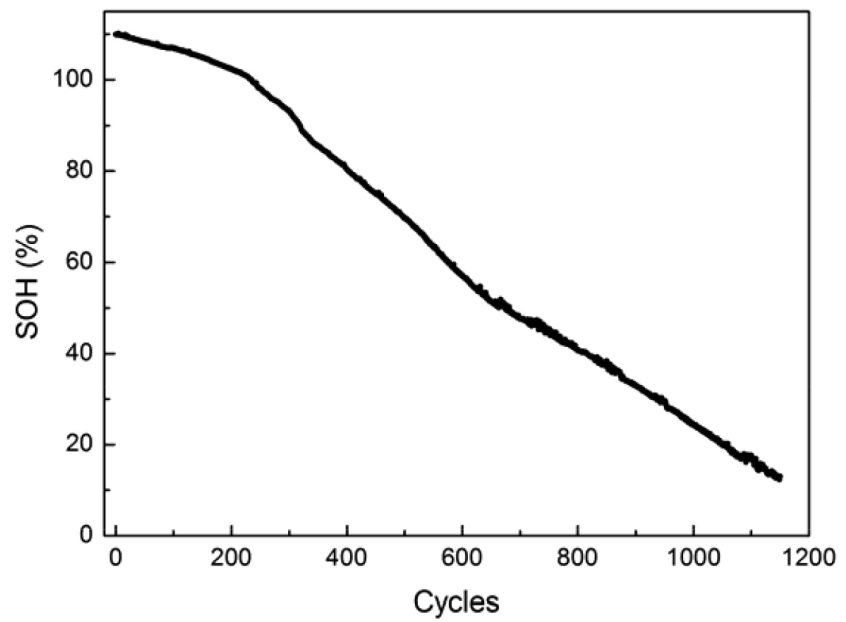

Figure 6. The battery SOH dependence upon continuous charge-discharge cycles. Note: the measured SOH in a pristine battery is higher than the nominal value furnished by the manufacturer

\section{CONCLUSION}

We show that to charge and discharge a portable lithium-ion battery between 3.0 and $4.2 \mathrm{~V}$ under low charging and discharging currents $(0.04 \mathrm{C}$ to $0.52 \mathrm{C})$, the stored and extracted charge (charge and discharge capacities), into and from the battery, decrease linearly with the intensity of the applied current. The time to charge or to discharge the battery between these voltages decreases with increasing applied current intensity, with a functional dependence fitted by an allometric function, as already obtained by Peukert for lead-acid batteries. Under discharge currents of low intensities battery coulometric efficiency higher than $97 \%$ was obtained. The results presented here may be useful to design batteries for portable electric devices, avoiding the fast deleterious effects of high current operations. It should be stressed that the cycling experiments were performed under the condition of very small change in the battery $\mathrm{SOH}$ value of the fresh battery $(\mathrm{SOH}=98 \%)$.

\section{ACKNOWLEDGMENTS}

The authors wish to thank Sercomtel Celular SA for providing the battery samples employed in this study. S. P. da Silva and J. Scarminio are grateful to the Conselho Nacional de Pesquisa (CNPq - Brazil) for their scholarships.

\section{REFERENCES}

1. Zhang, S. S.; Xu, K.; Jow, T. R.; J. Power Sources 2006, 160, 1403.

2. Reimers, J. N.; Dahn, J. R.; J. Electrochem. Soc. 1992, 139, 2091.

3. Zhang, S. S.; Xu, K.; Jow, T. R.; J. Power Sources 2006, 160, 1349.

4. Li, J.; Murphy, E.; Winnick, J.; Kohl, P.; J. Power Sources 2001, 102, 302.

5. Sikha, G.; Ramadass, P.; Haran, B. S.; White, R. E.; Popov, B. N.; J. Power Sources 2003, 122, 67.

6. Liu, Y.-H.; Teng, J.-H.; Lin, Y.-C.; IEEE Trans. Ind. Electron. Control Instrum. 2005, 52, 1328.

7. Zhang, S. S.; J. Power Sources 2006, 161, 1385.

8. Huang, S.-J.; Huang, B.-G.; Pai, F.-S.; IEEE Transactions on Power Electronics 2013, 28, 1555.

9. Lian-xing, L.; Xin-cun, T.; Yi, Q.; Hong-tao, L.; J. Cent. South Univ. Technol. (Engl. Ed.) 2011, 18, 319

10. Verma, P.; Maire, P.; Novák, P.; Electrochim. Acta 2010, 55, 6332.

11. Li, Z.; Huang, J.; Liaw, B. Y.; Metzler, V.; Zhang, J.; J. Power Sources 2014, 254, 168.

12. Legrand, N.; Knosp, B.; Desprez, P.; Lapicque, F.; Raël, S.; J. Power Sources 2014, 245, 208.

13. Jossen, A.; J. Power Sources 2006, 154, 530.

14. Scrosati, B.; Garche, J.; J. Power Sources 2010, 195, 2419.

15. Bernardi, D. M.; Go, J.-Y.; J. Power Sources 2011, 196, 412.

16. Ramadass, P.; Haran, B.; White, R.; Popov, B. N.; J. Power Sources 2002, 111, 210.

17. Guo, Z.; Liaw, B. Y.; Qiu, X.; Gao, L.; Zhang, C.; J. Power Sources 2015, 274, 957.

18. Floriano, R.; Santos, A. O.; Urbano, A.; Cardoso, L. P.; Scarminio, J.; Int. J. Res. Rev. Appl. Sci. 2013, 17, 158.

19. Doerffel, D., Sharkh, S. A.; J. Power Sources 2006, 155, 395.

20. Omar, N.; Van den Bossche, P.; Coosemans, T.; Van Mierlo, J.; Energies 2013, 6, 5625 . 